\title{
Corrigendum: Bored pile design in stiff clay ll: mechanisms and uncertainty
}

Paul J. Vardanega, Michael G. Williamson and Malcolm D. Bolton

Some errors appeared in this paper when it was published in Proceedings of the Institution of Civil Engineers - Geotechnical Engineering 165(4) 233-246, http://dx.doi.org/10.1680/geng.11.00063.

The caption of Figure 11 should refer to equation 35 not 34 as printed.
The caption of Figures 12 and 14 should refer to equation 40 not 39 as printed.

On page 243 line 5 equation 42 not 41 should be referred to.

On page 243 line 24 equation 40 not 39 should be referred to. 